\title{
Perbandingan Intubasi Endotrakea Menggunakan Clip-on Smartphone Camera Videolaryngoscope dengan Laringoskop Macintosh pada Manekin
}

\author{
Fariz Wajdi Latuconsina, ${ }^{1}$ Dedi Fitri Yadi, ${ }^{2}$ Suwarman ${ }^{2}$ \\ ${ }^{1}$ RSUD Scholoo Keyen Kabupaten Sorong Selatan, ${ }^{2}$ Departemen Anestesiologi dan Terapi Intensif \\ Fakultas Kedokteran Universitas Padjadjaran/RSUP Dr. Hasan Sadikin Bandung
}

\begin{abstract}
Abstrak
Intubasi endotrakea merupakan gold standard dalam manajemen jalan napas. Teknik laringoskopi direk merupakan teknik yang sulit sehingga berpotensi menyebabkan kegagalan khususnya pada orang yang tidak berpengalaman. Tujuan penelitian ini menilai keberhasilan, lama waktu, dan kemudahan intubasi endotrakea pada manekin menggunakan clip-on smartphone camera videolaryngoscope dibanding dengan laringoskop Macintosh. Penelitian dilakukan menggunakan metode crossover randomized study melibatkan 23 orang mahasiswa kedokteran di RSUP Dr. Hasan Sadikin Bandung pada Oktober 2017. Dari penelitian ini didapatkan keberhasilan intubasi endotrakea menggunakan clip-on smartphone camera videolaryngoscope lebih tinggi (96\%) dibandingkan dengan menggunakan laringoskop Macintosh (65\%). Lama waktu intubasi endotrakea rata-rata juga terbukti lebih singkat menggunakan clip-on smartphone camera videolaryngoscope (32 detik) dibanding dengan laringoskop Macintosh (52 detik). Intubasi endotrakea menggunakan clipon smartphone camera videolaryngoscope lebih mudah (4) dibanding dengan menggunakan laringoskop Macintosh (6). Ketiga variabel menunjukkan perbedaan yang signifikan dengan nilai $p<0,05$. Simpulan, penggunaan clip-on smartphone camera video laryngoscope untuk intubasi endotrakea memiliki keberhasilan yang lebih tinggi, lama waktu intubasi endotrakea yang lebih singkat, dan intubasi endotrakea yang lebih mudah dibanding dengan menggunakan laringoskop Macintosh.
\end{abstract}

Kata kunci: Clip-on smartphone camera videolaryngoscope, intubasi endotrakea, laringoskopi direk, videolaryngoscope

\section{Comparison of Clip-on Smartphone Camera Videolaryngoscope and Macintosh Laryngoscope for Endotracheal Intubation in Mannequins}

\begin{abstract}
Endotracheal intubation has been used as the gold standard in airway management. Direct laryngoscopy is a difficult technique with a potential failure especially when performed by non-experienced personnel. The aim of this study was to assess the efficacy, duration, and ease of endotracheal intubation in mannequins using a clip-on smartphone camera videolaryngoscope compared to the use of Macintosh laryngoscope. This was a randomized crossover study involving 23 medical students at Dr. Hasan Sadikin General Hospital in October 2017. This study showed higher intubation success with clip-on smartphone camera videolaryngoscope (96\%) compared to Macintosh laryngoscope (65\%). Mean duration of intubation using clip-on smartphone camera videolaryngoscope was faster (32 seconds) compared to Macintosh laryngoscope (52 seconds). Endotracheal intubation using clip-on smartphone camera videolaryngoscope was easier to perform (4) compared to Macintosh laryngoscope (6). All three variables showed significant differences with $\mathrm{p}<0.05$. In conclusion, this study showed that the use of clip-on smartphone camera videolaryngoscope for endotracheal intubation has a higher success rate, can be performed in a shorter duration, , and easier to do for endotracheal intubation compared to the use of Macintosh laryngoscope.
\end{abstract}

Key words: Clip-on smartphone camera videolaryngoscope, direct laryngoscopy, endotracheal intubation, video-laryngoscope

Korespondensi: Fariz Wajdi Latuconsina, dr., SpAn, RSUD Scholoo Keyen Kabupaten Sorong Selatan, Unnamed Road, Papua Bar. 98454, Keyen, Teminabuan, Kabupaten Sorong Selatan, Papua Barat. 98454 Email fariz1403@gmail.com 


\section{Pendahuluan}

Intubasi endotrakea merupakan prosedur definitif terhadap jalan napas untuk resusitasi dan manajemen jalan napas. ${ }^{1}$ Masalah yang terjadi saat intubasi endotrakea dapat menyebabkan komplikasi yang serius dan pada beberapa kasus dapat mengancam jiwa. ${ }^{2,3}$

Laringoskopi direk menggunakan bilah Macintosh merupakan teknik intubasi endotrakea dan dipertimbangkan sebagai gold standard. ${ }^{1,4-6}$ Teknik yang dibutuhkan untuk melakukan laringoskopi direk sangat kompleks dan sulit untuk dikuasai dikarenakan individu yang melakukan harus mampu meluruskan aksis antara oral, faring, dan trakea sehingga dapat memvisualisasi glotis. ${ }^{2,3}$ Oleh karena itu, intubasi endotrakea menggunakan laringoskopi direk yang dilakukan oleh tenaga medis memiliki risiko tinggi terjadi kegagalan. ${ }^{5}$

Video-laryngoscopy akan meningkatkan lapang pandang struktur laring dibanding dengan visualisasi langsung menggunakan laringoskop Macintosh. ${ }^{1,-9}$ Teknik intubasi endotrakea menggunakan video-laryngoscopy indirek membutuhkan kemampuan yang lebih sedikit. ${ }^{10}$ Alat penunjang video-laryngoscopy yang dijual secara komersial seperti C-MAC (Karl Storz Gmbh \& Co), glidescope (verathon medical inc), airtraq (prodol meditec), ambupentax-AWS (ambu/AS), mcgrath (aircraft medical Ltd), dan king vision laryngosocpe (king systems) memiliki harga yang mahal berkisar ribuan Dolar Amerika sehingga membatasi pengunaannya. ${ }^{7}$

Smartphone endoscope camera merupakan salah satu alat yang dapat digunakan dalam dunia medis dengan sedikit modifikasi atau pengembangan. ${ }^{1}$ Penelitian yang sudah dilakukan menunjukkan keberhasilan intubasi endotrakea pada manekin yang dilakukan oleh praktisi medis menggunakan smartphone endsocope camera yang ditempelkan pada laringoskop Macintosh. ${ }^{11}$ Salah satu kekurangan penelitian yang telah dilakukan sebelumnya dibutuhkan waktu yang cukup lama untuk menentukan lokasi maupun arah kamera yang sesuai untuk memastikan posisi kamera. Masalah ini dapat ditanggulangi dengan mengembangkan bilah laringoskop menjadi bentuk tertentu yang memiliki ruang untuk meletakkan endoscope camera sehingga alat tersebut dapat digunakan. ${ }^{11}$

Peneliti mengembangkan alat tambahan berupa clip-on smartphone camera pada laringoskop Macintosh. Dengan penambahan alat ini, smartphone endoscope camera dapat berperan sebagai video-laryngoscope dan diharapkan dapat membantu tenaga medis khususnya yang belum terlatih untuk melakukan tindakan intubasi endotrakea. Penelitian ini bertujuan mengetahui keberhasilan intubasi endotrakea, lama waktu intubasi endotrakea, dan tingkat kemudahan intubasi endotrakea pada manekin menggunakan clip-on smartphone camera videolaryngoscope dibanding dengan laringoskop Macintosh yang dilakukan oleh tenaga medis yang tidak terlatih.

\section{Subjek dan Metode}

Penelitian ini merupakan penelitian randomized crossover study mengenai keberhasilan, lama waktu, dan kemudahan intubasi endotrakea pada manekin dengan menggunakan clip-on smartphone camera videolaryngoscope dibanding dengan laringoskop Macintosh pada mahasiswa program profesi dokter Fakultas Kedoteran Universitas Padjadjaran. Penelitian dilakukan pada bulan Oktober 2017 di RSUP Dr. Hasan Sadikin Bandung.

Kriteria inklusi subjek penelitian ini adalah mahasiswa Program Pendidikan Profesi Dokter FK Unpad yang sedang menjalani rotasi di Departemen Anestesiologi dan Terapi Intensif RSUP Dr. Hasan Sadikin Bandung dan belum pernah melakukan tindakan intubasi endotrakea sebelumnya. Kriteria eksklusi, yaitu subjek memiliki keterbatasan fisik saat dilakukan penelitian. Penentuan besar sampel dilakukan berdasar atas perhitungan statistik dengan menetapkan taraf kepercayaan 95\% dan uji kuasa (power test) 95\%. Penentuan besar sampel menggunakan rumus untuk penelitian analisis 
kategorik numerik berpasangan. Pemilihan subjek penelitian berdasar atas consecutive sampling, yaitu mengambil setiap subjek penelitian yang memenuhi kriteria inklusi dan tidak termasuk kriteria eksklusi berdasar atas urutan kedatangan subjek. Subjek penelitian terdiri atas 23 orang mahasiswa. Dilakukan randomisasi urutan penggunaan alat untuk melakukan intubasi endotrakea.

Clip-on smartphone camera adalah kamera eksternal dengan media visualisasi berupa smartphone yang dimodifikasi dengan menambahkan alat penjepit sebagai docking pada laringoskop Macintosh. Pemasangan dilakukan dengan cara memasukkan kamera ke dalam alat penjepit yang kemudian dijepitkan pada bilah Macintosh. Ujung kamera berada $30 \mathrm{~mm}$ dari ujung bilah Macintosh. Selanjutnya, kamera dihubungkan dengan smartphone sesuai dengan gambar 1. Pengoperasian kamera eksternal pada smartphone menggunakan aplikasi Scopecam (WiFi Electronics Co., Ltd.)

Penelitian dilakukan setelah mendapatkan persetujuan Komite Etik Penelitian Kesehatan Fakultas Kedokteran Universitas Padjadjaran/ RSHS. Subjek penelitian akan mendapatkan penjelasan secara verbal dan demonstrasi mengenai intubasi endotrakea menggunakan kedua alat. Selanjutnya, subjek akan mencoba melakukan intubasi endotrakea menggunakan kedua alat sebanyak satu kali sebagai proses pengenalan. Setelah itu, subjek penelitian akan melakukan intubasi endotrakea pada manekin menggunakan kedua alat. Pengambilan data hasil penelitian berupa keberhasilan intubasi endotrakea, lama waktu intubasi endotrakea, dan kemudahan intubasi endotrakea menggunakan kedua alat.

Keberhasilan intubasi endotrakea didefinisikan sebagai intubasi endotrakea yang dilakukan kurang dari 2 menit dan pipa endotrakea masuk ke dalam trakea. Lama waktu intubasi endotrakea adalah waktu yang dibutuhkan sejak dimulainya insersi bilah laringoskop di antara kedua gigi seri hingga balon pipa endotrakea melewati pita suara. Kemudahan intubasi endotrakea dinilai secara subjektif oleh subjek penelitian pada skala 0 (sangat mudah) sampai 10 (sangat sulit).

Analisis data meliputi analisis deskriptif dan uji hipotesis. Data disajikan dalam bentuk persentase (\%) untuk variabel kategorik dan median untukvariabel numerik. Untuk variabel kategorik, uji statistik dilakukan dengan uji McNemar. Untuk variabel numerik, uji statistik dilakukan dengan uji Wilcoxon. Data diolah dengan program statistical product and service solution (SPSS) versi 24.0 for windows.

Tabel Perbandingkan Keberhasilan, Lama Waktu, dan Kemudahan Intubasi Endotrakea pada Kedua Alat

\begin{tabular}{|c|c|c|c|}
\hline Variabel & $\begin{array}{c}\text { Laringoskopi Direk } \\
\text { (Laringoskop Macintosh) }\end{array}$ & $\begin{array}{c}\text { Videolaryngoscopy dengan } \\
\text { Clip-on Smartphone } \\
\text { Camera }\end{array}$ & Nilai p \\
\hline & $n=23$ & $n=23$ & \\
\hline $\begin{array}{l}\text { Keberhasilan intubasi endotrakea } \\
\text { Berhasil } \\
\text { Tidak berhasil }\end{array}$ & $\begin{array}{c}15 \\
8\end{array}$ & $\begin{array}{c}22 \\
1\end{array}$ & $0,016^{*}$ \\
\hline $\begin{array}{l}\text { Lama intubasi endotrakea (detik) } \\
\text { Rata-rata } \pm \text { SD } \\
\text { Median }\end{array}$ & $\begin{array}{c}60,04 \pm 19,89 \\
58\end{array}$ & $\begin{array}{l}37 \pm 10,78 \\
32\end{array}$ & $0,0001^{*}$ \\
\hline $\begin{array}{l}\text { Kemudahan penggunaan alat } \\
\text { Rata-rata } \pm \text { SD } \\
\text { Median }\end{array}$ & $6,21 \pm 1,16$ & $\begin{array}{c}3,60 \pm 1,07 \\
4\end{array}$ & $0,0001^{*}$ \\
\hline
\end{tabular}




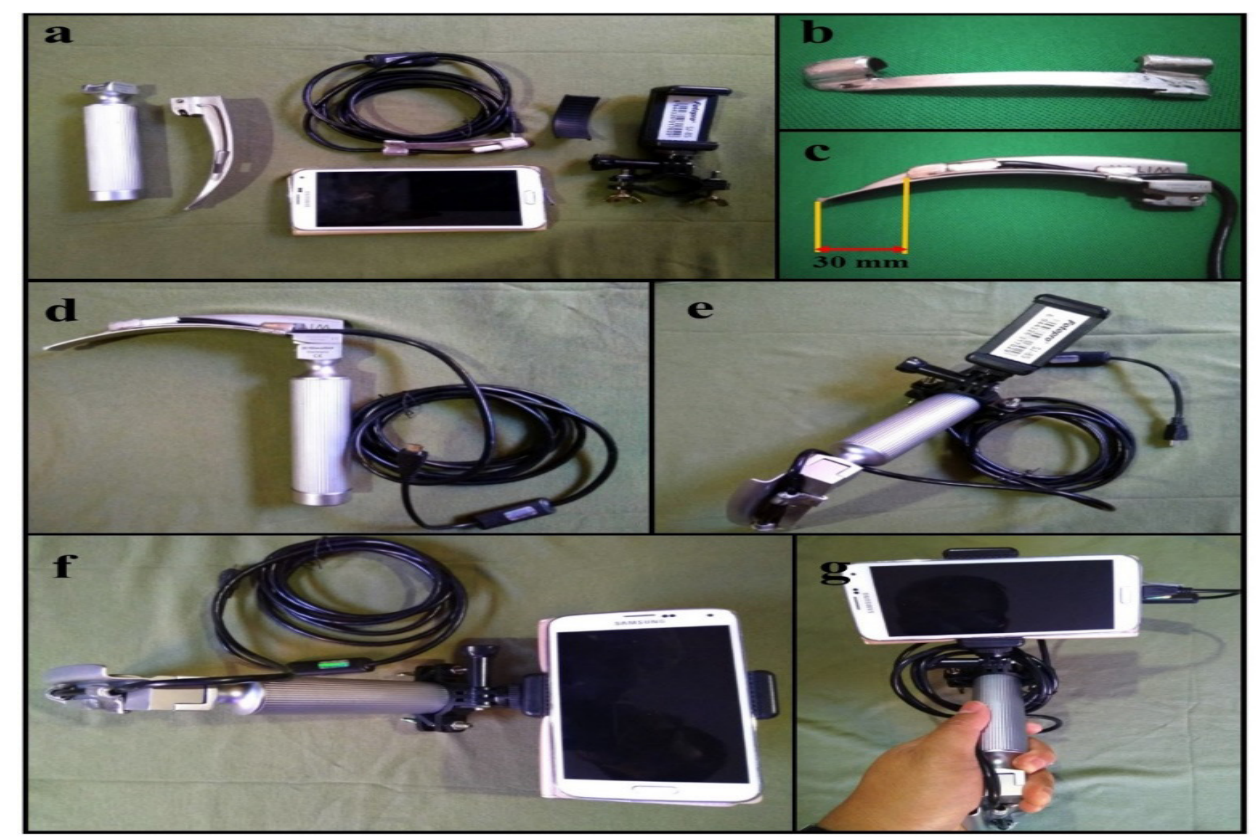

Gambar 1 Clip-on Smartphone Camera Video-laryngoscope

Ket.: Alat disiapkan berupa laringoskop Macintosh, clip-on smartphone camera, smartphone Samsung Galaxy S5, docking smartphone fotopro SJ-85 (a). Smartphone camera dipasang pada alat penjepit (b) yang selanjutnya dijepitkan pada bilah Macintosh (c). Jarak ujung kamera terhadap ujung bilah sebesar $30 \mathrm{~mm}$. Bilah Macintosh yang sudah dipasangkan clip-on smartphone camera dipasangkan pada handle (d). Pada handle laringoskop dipasangkan docking untuk smartphone (e). Kemudian smartphone dipasangkan pada docking tersebut dan disambungkan dengan clip-on smartphone camera (f)

Sumber: Dokumentasi pribadi

\section{Hasil}

Dua puluh tiga mahasiswa pendidikan profesi dokter mengikuti penelitian ini. Seluruh subjek melakukan intubasi endotrakea menggunakan kedua alat. Tidak ada data yang dieksklusikan dan dikeluarkan. Seluruh subjek belum memiliki pengalaman intubasi endotrakea sebelumnya.

Keberhasilan intubasi endotrakea menggunakan clip-on smartphone camera videolaryngoscope pada seluruh subjek, sedangkan keberhasilan intubasi endotrakea menggunakan laringoskop Macintosh sebesar 15 dari 23. Hal ini menunjukkan perbedaan bermakna secara statistik ( $<<0,05$; Gambar 2). Lama waktu intubasi endotrakea lebih singkat menggunakan clip-on smartphone camera videolaryngoscope selama 32 detik, sedangkan intubasi endotrakea menggunakan laringoskop Macintosh selama 58 detik.
Terdapat perbedaan bermakna pada kedua kelompok $(\mathrm{p}<0,05$; Tabel).

Intubasi endotrakea menggunakan clipon smartphone camera videolaryngoscope dianggap lebih mudah dengan skor kemudahan sebesar 4 dibanding dengan menggunakan laringoskop Macintosh dengan skor kemudahan sebesar 6. Terdapat perbedaan bermakna antara kedua kelompok $(\mathrm{p}<0,005$; Tabel).

\section{Pembahasan}

Penggunaan smartphone endosocope camera sebagai media video-laryngoscope berbasis bilah Macintosh telah dilakukan pada penelitian sebelumnya. Modifikasi dilakukan dengan cara merekatkan smartphone endoscope camera pada bilah Macintosh. Jarak ujung kamera terhadap ujung bilah Macintosh sebesar 30 $\mathrm{mm}$. Kemudian, kamera dihubungkan dengan 


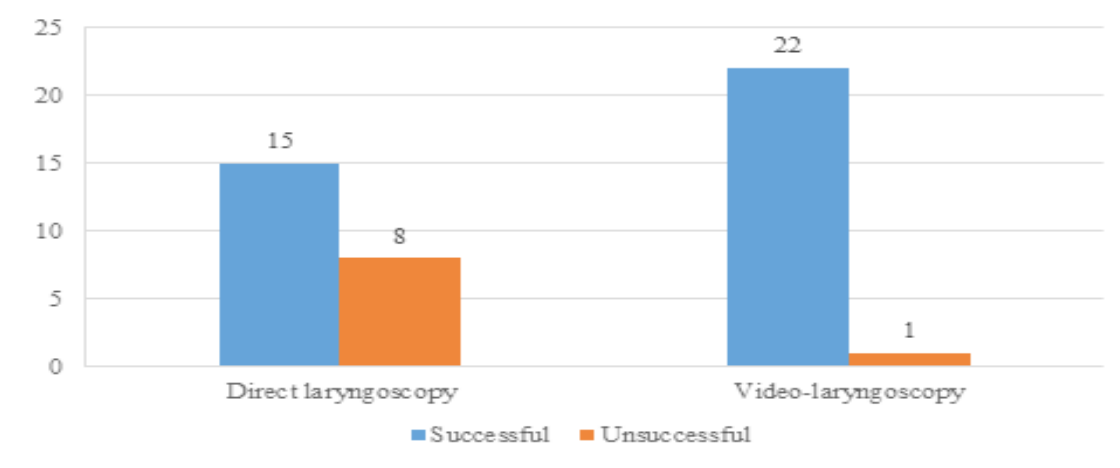

Gambar 2 Grafik Keberhasilan Intubasi Endotrakea Menggunakan Laringoskop Macintosh dan Clipon Smartphone Camera Videolaryngoscope

sebuah smartphone sebagai penampil gambar. Kekurangan pada penelitian sebelumnya adalah dibutuhkan waktu untuk menyesuaikan posisi kamera.,11 Pada penelitian ini, kami membuat sebuah lempeng penjepit berbahan dasar baja nirkarat sebagai docking bagi smartphone endoscope camera. Jarak ujung kamera terhadap ujung bilah dibuat sama dengan penelitian sebelumnya, yaitu $30 \mathrm{~mm}$.

Pada teknik laringoskopi direk, tantangan yang dihadapi adalah membuat visualisasi secara garis lurus dengan struktur laring dan memasukkan pipa endotrakeal ke arah glotis tanpa mengganggu visualisasi struktur laring. Untuk memvisualisasi laring, diperlukan keselarasan aksis oral, faring, dan laring. Penglihatan secara garis lurus terhadap struktur laring didapatkan secara mekanik dengan mengontrol posisi lidah dan epiglotis menggunakan laringoskop. Pada saat pipa endotrakeal dimasukkan, terdapat risiko terhalangnya pandangan operator terhadap struktur glotis. Beberapa penelitan menunjukkan kesulitan mendapatkan dan menjaga keterampilan intubasi, khususnya ketika kesempatan melakukan intubasi endotrakea terbatas. ${ }^{2,5,12}$ Keuntungan utama dari video-laryngoscope adalah kamera pada ujung bilah membuat keselarasan aksis oral, faring, dan laring tidak dibutuhkan. Videolaryngoscope memproyeksikan gambaran struktur lidah dan laring tanpa harus membuat pandangan secara garis lurus terhadap struktur laring secara mekanik. Keuntungan ini membuat intubasi endotrakea lebih cepat dan lebih mudah. .,12-14 $^{2}$

Penelitian ini menunjukkan keberhasilan endotrakea menggunakan clip-on smartphone camera videolaryngoscope lebih tinggi dibanding dengan menggunakan laringoskop Macintosh. Hal ini mungkin disebabkan oleh video-laryngoscopes menggunakan kamera yang difokuskan terhadap laryngeal inlet untuk memproyeksikan gambar sedekatdekatnya dari pita suara. Penggunaan videoassisted laryngoscopy akan memberikan gambaran struktur laring yang lebih baik dibanding dengan visualisasi langsung dari laringoskopi direk. ${ }^{4,15}$ Hal yang sama juga diperlihatkan pada beberapa penelitian lain yang menunjukkan keberhasilan intubasi endotrakea mengunakan video-laryngoscope berbasis bilah Macintosh lebih baik dibanding dengan menggunakan laringoskop Macintosh. ${ }^{2,16}$

Hasil penelitian ini memperlihatkan bahwa intubasi endotrakea menggunakan clip-on smartphone camera videolaryngoscope lebih singkat dan lebih mudah dibanding dengan menggunakan laringoskop Macintosh. Hal ini sesuai dengan penelitian sebelumnya yang menunjukkan intubasi endotrakea menggunakan videolaryngoscope berbasis bilah Macintosh lebih mudah dan lebih singkat dibanding dengan menggunakan laringoskop Macintosh. 2,17 
Namun demikian, penggunaan videolaryngoscope akan menyulitkan saat melakukan insersi pipa endotrakeal. Hal ini dikarenakan penglihatan 2 dimensi dari layar sehingga diperlukan koordinasi matatangan yang baik. Selain itu, masih diperlukan intubation stylet untuk membentuk pipa endotrakeal sesuai dengan kurvatura jalan napas. ${ }^{13,18}$ Kesulitan ini dibuktikan dengan terdapat satu kegagalan intubasi endotrakea menggunakan clip-on smartphone camera. Kegagalan terjadi karena lama waktu intubasi endotrakea melebihi 120 detik.

Terdapat beberapa keterbatasan pada penelitian ini. Pertama, penelitian ini dilakukan pada manekin sehingga hasil penelitian ini tidak secara langsung menggambarkan situasi klinis yang mungkin terjadi di lapangan. Namun demikian, manekin sudah pernah digunakan pada beberapa penelitian sejenis sehingga penggunaannya sudah terstandar. Keterbatasan yang kedua, penelitian ini tidak membandingkan clip-on smartphone camera videolaryngoscope dengan alat videolaryngoscope yang sudah digunakan secara luas.

\section{Simpulan}

Penggunaan clip-on smartphone camera videolaryngoscope memberikan keberhasilan intubasi endotrakea yang lebih baik, lama waktu intubasi endotrakea lebih singkat, dan intubasi endotrakea lebih mudah dibanding dengan menggunakan laringoskop Macintosh pada manekin.

Penelitian lebih lanjut mengenai intubasi endotrakea menggunakan clip-on smartphone camera videolaryngoscope pada simulasi jalan napas sulit perlu dilakukan untuk melihat kegunaan alattersebutpada kondisi jalan napas sulit. Selain itu, perlu dilakukan uji kemanan penggunaan alat pada manusia dan penelitian mengenai intubasi endotrakea menggunakan alat ini pada manusia. Penelitian lain untuk membandingkan clip-on smartphone camera videolaryngoscope dengan videolaryngoscope yang sudah terstandar juga perlu dilakukan. Peneliti menilai clip-on smartphone camera videolaryngoscope dapat dijadikan alternatif media videolaryngoscope.

\section{Daftar Pustaka}

1. Hodgetts V, Danha RF, Mendonca C, Hillerman C. A randomized comparison of C-MAC videolaryngoscope versus Macintosh laryngoscope for tracheal intubation. J Anesthesia Clinic Res. 2011;2(9):1-3.

2. Shin M, Bai SJ, Lee KY, Oh E, Kim HJ. Comparing McGrath MAC, C-MAC, and Macintosh laryngoscopes operated by medical students: a randomized, crossover, manikin study. Bio Med Res Int. 2016;2016:1-8.

3. Ray DC, Billington C, Kearns PK, Kirkbride $\mathrm{R}$, Mackintosh K, Reeve CS, dkk. A comparison of McGrath and Macintosh laryngoscopes in novice users: a manikin study. Anaesthesia. 2009;64:1207-10.

4. Liu Z-J, Yi J, Guo W-J, Ma C, Huang Y-G. Comparison of MacGrath series 3 and Macintosh laryngoscopes for tracheal intubtion in patients with normal airway by inexperienced anesthetists. Medicine. 2016;95(2):1-6.

5. Kaki AM, AlMarakbi WA, Fawzi HM, Boker AM. Use of Airtraq, C-Mac, and glidescope laryngoscope is better than Macintosh in novice medical student's hands: a manikin study. Saudi J Anaesth. 2011;5(4):376-81.

6. Wallace CD, Foulds LT, McLeod GA, Younger RA, McGuire BE. A comparison of the ease of tracheal intubation using a McGrath MAC laryngoscope and a standard Macintosh laryngoscope. Anaesthesia. 2015;70:1281-5.

7. Karippacheril JG, Umesh G, Ramkumar V. Inexpensive video-laryngoscopy guided intubation using a personal computer: Initial experience of a novel technique. J Clin Monit Comput. 2014;28:261-4.

8. Hagberg CA, Artime CA. Airway management in the adult. Dalam: Miller RD, Cohen NH, Eriksson LI, Fleisher LA, Wiener-Kronish JP, Young WL, penyunting. Miller's anesthesia. Edisi ke- 
8. Philadelphia: Elsevier Saunders; 2015. hlm. 1647-83.

9. Kelly FE, Cook TM. Seeing is believing: getting the best out of videolaryngoscopy. Br J Anaesth. 2016;117(S1):19-13.

10. Biermann H, Heiden EVD, Beishuizen A, Girbes ARJ, Waard MCd. Endotracheal intubation by inexperienced registrars in internal medicine: a comparison of videolaryngoscopy versus direct laryngoscopy. Neth J Crit Care. 2013;17(5):7-9.

11. Lee C-J, Cho S-H, Kim J-S. Endotracheal intubation using smartphone endoscope camera. Asian Pac J Health Sci. 2016;3(2):19-21.

12. Levitan RM, Heitz JW, Sweeney M, Cooper RM. The complexities of tracheal intubation with direct laryngoscopy and alternative intubation devices. Ann Emerg Med. 2011;57(3):240-7.

13. Chemsian RV, Bhananker S, Ramaiah R. Videolaryngoscopy. Int J Crit Illn Inj Sci. 2014;4(1):35-42.

14. Liew LQ, Teo WW, Tan BH, Leong SM, Tan AY. Ease of intubation with the
McGRATH $®$ MAC, C-MAC $®$ or Macintosh laryngoscopes by novice operators in simulated difficult airways-a manikin study. BJMMR. 2016;16(8):1-6.

15. Collins SR. Direct and indirect laryngoscopy: equipment and techniques. Respir Care. 2014;59(6):850-64.

16. Pieters BMA, Wilbers NER, Huijzer M, Winkens B, Zundert AAJV. Comparison of seven videolaryngoscopes with the Macintosh laryngoscope in manikins by experienced and novice personnel. Anaesthesia. 2016;71:556-64.

17. Lye ST, Liaw CM, Seet E, Koh KF. Comparison of results from novice and trained personnel using the Macintosh Laryngoscope, Pentax AWS $®, C-M A C^{\mathrm{TM}}$, and Bonfils Intubation Fibrescope: a manikin study. Singapore Med J. 2013;54(2):64-8.

18. Niforopoulou P, Pantazopoulos I, Demestiha T, Koudouna E, Xanthos T. Video-laryngoscopes in the adult airway management: a topical review of the literature. Acta Anaesthesiol Scand. 2010;54:1050-61. 